\title{
A Study on Challenges and Opportunities in Master Data Management.
}

\author{
Tapan kumar Das ${ }^{1}$ and Manas Ranjan Mishra \\ ${ }^{1}$ SITE, VIT University, Vellore, TN, India \\ tapan.das@vit.ac.in \\ ${ }^{2}$ IBM India Pvt .Ltd, Bangalore, India \\ mmishra9@in.ibm. com
}

\begin{abstract}
This paper aims to provide a data definition of one master data for cross application consistency. The concepts related to Master data management in broader spectrum has been discussed. The current challenges companies are facing while implementing the MDM solutions are outlined. We have taken a case study to highlight why Master Data Management is imperative for the enterprises in optimizing their business Also we have identified some of the long term benefits for the enterprises on implementing MDM..
\end{abstract}

\section{Keywords}

Data quality, Information system, Unstructured, Transactional data

\section{Introduction}

The increasing amount of data is creating challenges to companies' data management practices, causing data quality problems which are very common in companies now-a days $[3,9,10]$. The life cycle of a typical product involves different phases like design, material acquisition, manufacture, distribution, sale, use, service and termination. Each stage requires different data which need to be managed in an integrated and systematic manner to provide accurate information at the right time to various stakeholders [15,22].Workgroups, such as organization departments, develop data processes in silos which lead to variance in the business concepts and object definitions [14]. The need to share information across the organizations and supply chains is driving data from silos to be exposed, unified and shared. This reveals enormous data discrepancies and incompatibilities [2,7].It is important to note that although data warehousing and business intelligence are an absolutely essential part of modern information technology and have brought great value to business decision-making and operational efficiencies, these solutions often did not create the desired 'single view of the business'[6].

The companies have been facing the challenges of getting the single view of business data from hundreds of data entry terminals. Master Data Management are the key. It fixes the data quality problem on the operational side of the business .It augments and operate the data warehouse on the analytical side of the business [6]. Twenty five years after data ware housing's inception, a recent survey found that a common top ten CIO request is to get a 'single view of the customer'. One analyst reports " $75 \%$ of leading companies are incapable of creating a unified view of their

DOI: $10.5121 / \mathrm{ijdms} .2011 .3209$ 
International Journal of Database Management Systems ( IJDMS ), Vol.3, No.2, May 2011

customer[4].This is because, as we saw in earlier sections, the Master data consists of facts that define a business entity, facts that may be used to model one or more definitions or views of an entity. Entity definitions based on master data provide business consistency and data integrity when multiple IT systems across an organization (or beyond) identify the same entity differently.

Business analytics get more relevant and competitive information from big data warehouses, but the data sources still remain inconsistent. These data quality issues affect operational efficiency and also produce inaccurate reports.

The purpose of this paper is to get an insight about practical difficulties in MDM space. In addition to that, this study is an attempt for understanding the concept of MDM and its meaning in business context as a whole. Also we have identified the opportunities in this landscape.

The study addresses the issue in consensus driven approach. We first reviewed the literature, then case study analysis and finally by experts interviews.

\section{Literature review on MDM and related concepts}

\subsection{Master data}

Master Data is the critical business information related to the transactional and analytical operations of the enterprise. Master Data Management (MDM) is a combination of applications and technologies that consolidates, cleans, augments corporate data and synchronizes it with all applications, business processes, and analytical tools. This results in significant improvements in operational efficiency, accurate reporting and strategic decision making[6].

Master data describes the business-oriented properties of data objects which are used in the different applications across the organization together with their associated metadata, attributes, definitions, roles, connections and taxonomies [5,11].Master data is the data that has been cleansed, standardized and integrated into an enterprise-wide system [1] and used across multiple business domain. Core entities are parties (organization, customer, prospect, people, citizens, employees, vendors, suppliers or trading partners), places (locations, offices, regional alignments or geographies) and things (accounts, assets, policies, product or services) [14,20].

There are essentially five types of data in corporations [21]:

- Unstructured-This data is found in e-mail, white paper, magazine articles, corporate intranet portals, product specifications, marketing collateral, and PDF files.

- Transactional-This data is related to sales, orders, invoices, entries, claims.

- Metadata - This is data about data in data warehouse. It may reside in repository or in various other forms such as XML documents, report definitions, column descriptions in a $\log$ file.

- Hierarchical-Hierarchical data s tores the relationships between other data. It may be stored separately as descriptions of real-world relationships such as company organizational structures or product lines. 
International Journal of Database Management Systems ( IJDMS ), Vol.3, No.2, May 2011

- Master-Master data is the key to business and fall generally into four categories: people, things, places, and concepts. Further they are grouped along subject areas, domain areas, or entity types. For example, within people, there are customer, employee, and third party personnel. Within things, there are product, store, commodity and asset. Within concepts, there are things like agreement, warrantee, and licenses. Finally within places, there are office locations, sites and geographic divisions. Some of these domain areas may be further divided. Customer may be further segmented based on priority, credits. Product may be further segmented by category, sector and industry.

\subsection{Master data management}

\subsubsection{Definition}

Master Data Management (MDM) is the technology, tools, and processes required to create and maintain clean, consistent and accurate lists of master data. MDM tackles master data management in the operational area, managing it in the most appropriate place. MDM is complementary to business intelligence and provide an excellent source of dimensional data [16]. "MDM is the latest attempt to solve the old problem of inconsistent versions of critical data at the centre of an organization," said Andrew White, research vice president at Gartner summit 2011[8].

Product data management (PDM) systems are used to manage all product-related data and also product master data. Customer data integration (CDI) systems are used to manage customer master data. The customer in CDI is used as a generic term, which can mean also a client, contact, party, counterparty, patient, subscriber, supplier, prospect, service provider, citizen, guest, legal entity, trust, business entity and other [1]

Emphasis on data quality, integration, single version of the truth, data stewardship [12] MDM is not just a technological problem. In many cases, fundamental changes to business process will be required to maintain clean master data, and some of the most difficult MDM issues are more political than technical.MDM includes both creating and maintaining master data. Investing a lot of time, money, and effort in creating a clean, consistent set of master data is a wasted effort unless the solution includes tools and processes to keep the master data clean and consistent as it is updated and expanded [13].

Master Data Management has two architectural components [4]:

1. The technology to profile, consolidate and synchronize the master data across the enterprise 2. The applications to manage, cleanse, and enrich the structured and unstructured master data 
International Journal of Database Management Systems ( IJDMS ), Vol.3, No.2, May 2011

\subsubsection{MDM Phases}

An MDM project plan is associated with requirements, priorities, resource availability, time frame, and the size of the problem. According to Roger Wolter ,Microsoft Inc[21], most MDM projects include at least these phases:

1. Identify sources of master data.

2. Figure out the consumers of the master data.

3. Collect and analyze metadata for your master data.

4. Appoint data stewards.

5. Implement a data-governance program and data-governance council

6. Develop the master-data model.

7. Choose a toolset.

8. Design the infrastructure.

9. Generate and test the master data.

10. Modify the producing and consuming systems.

11. Implement the maintenance processes.

\subsubsection{MDM Solution Types}

MDM solutions in most organizations are built into or closely associated with a larger application, it also spans across multiple applications. MDM solutions fall into three broad categories [4]:

- Operational MDM

- Analytic MDM

- Enterprise MDM

\subsubsection{Characteristics of MDM solution.}

According to David Butler ,Oracle Inc[4], in order to successfully manage the master data, support corporate governance, and augment SOA systems, the MDM applications must have the following characteristics:

- A flexible, extensible and open data model to hold the master data and all associated metadata

- The data model must be application neutral and support OLTP sources.

- Metadata management capability .

- A source system management capability to fully cross-reference business objects and to satisfy seemingly conflicting data ownership requirements.

- A data quality system that can find and eliminate duplicate data .

- A data quality interface to prevent new errors from entering the system.

- A continuing data cleansing function to keep the data up to date.

- An internal triggering mechanism to create and deploy change information to all connected systems. 
International Journal of Database Management Systems ( IJDMS ), Vol.3, No.2, May 2011

- A comprehensive data security system to administer and monitor data access, update , and maintain change history.

- A user interface to support casual users and naïve users.

- A data migration management capability to insure consistency as data moves across the applications.

- A business intelligence platform to support profiling, compliance, audit and business performance indicators.

- A single platform to manage all master data objects.

- Analytical capability for directly analyzing master data.

\section{Case Study: European Bank [19]}

\section{The Situation}

- Big financial group and they have offices in multiple locations. They aid to personal and commercial clients.

- Inefficient sales support, due to:

- Fragmented data -lack of holistic customer view.

- Legacy approach where products drive customer data.

- Business units not talking to each other.

- No single customer view, duplicate records exist for different products.

- Contact management is not effective; offers are not communicated to potential clients.

- Low ROI due to rise in contact and campaign costs.

- Missing campaign management, difficulty in tracking customer buying pattern,retention .

- The organization wanted to move from product-centric to customer-centric business model.

- MDM tools and practices were selected as the methodology to implement the new business model

\section{The Challenges}

- Business Involvement

- How all business stakeholders would be involved in the implementation and execution?

- Efficiency of the data quality process

- How to improve the existing level of data quality?

- How to apply data quality improvements so that user would be successful?

- Level of primary system integration

- To what extent the primary systems would be modified - user interface, master data storage and APIs?

\section{The Approach}

\section{I . Architecture:}

- CDI database designed and implemented for unified customer data.

- Primary systems gave up their master data storage to common data layer.

- Master data migrated to the CDI database one primary system at a time.

- Original client data management interfaces decommissioned. 


\section{Business Process:}

- Data quality business process implemented, it is supported by new DQ workflow.

- Based on documented business rules, data quality refined offline

- Multiple business user groups -domain experts, call center, customer relationship managers - made accountable for DQ.

- DQ review and correction from time to time assigned to business users.

- KPIs and compensation incentives introduced for timely DQ review and correction such as number of records managed daily, number of business users involved ,average response time.

\section{Solution}

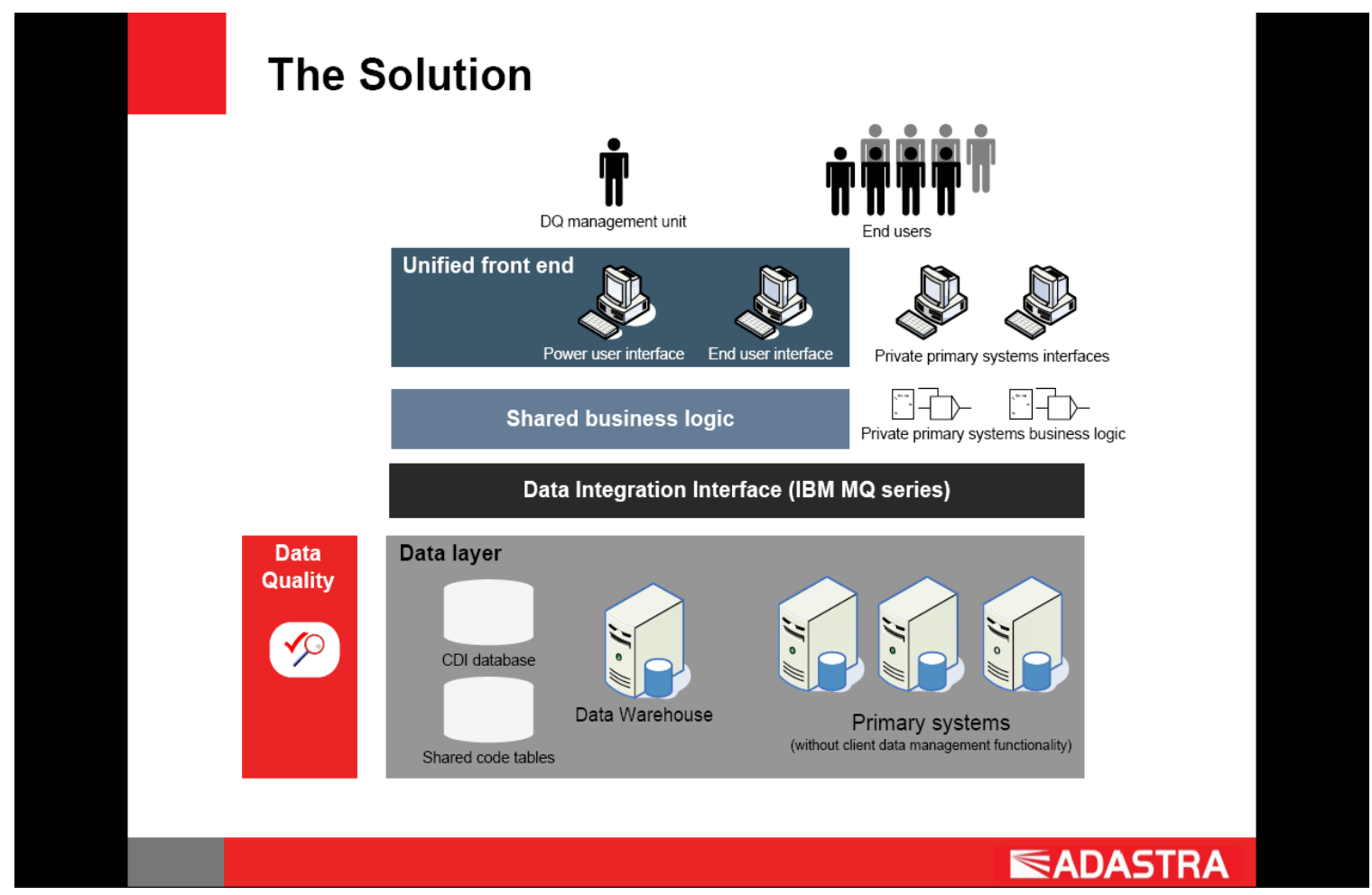

Figure.1.The MDM solution

\section{The Benefits}

- Business processes transformed to customer-centric.

- Sales and Marketing shoot up with better cross / up sell opportunities.

- Enabling targeted client and event driven campaign for specific types of clients.

- Streamlined client facing operations.

- Customer data platform managed and inteoi with unified customer data interface.

- Improved data quality and data issue resolution workflow.

- Significantly increased business involvement. 


\section{Research Methodology}

MDM has been studied by the wide spectrum of existing literature collected from diversified sources. Then one case study from real world has been analyzed. It shows how end-to-end implementation of MDM solution has helped the organization to come out of crisis.

Now we present a summary of interview of industry executives. We prepared a questionnaire and interacted them in face to face. As the MDM solution is mostly implemented for master data e.g. customer, product, employee. So to gain an insight of relevant master data, we took the help of TDWI data collected from 741 respondents from different companies. We believe the credential of the survey as the leaders in the market like Informatica, Business Objects, Teradata, Actuate have sponsored and participated in that survey.

Fig.2 Findings of the survey

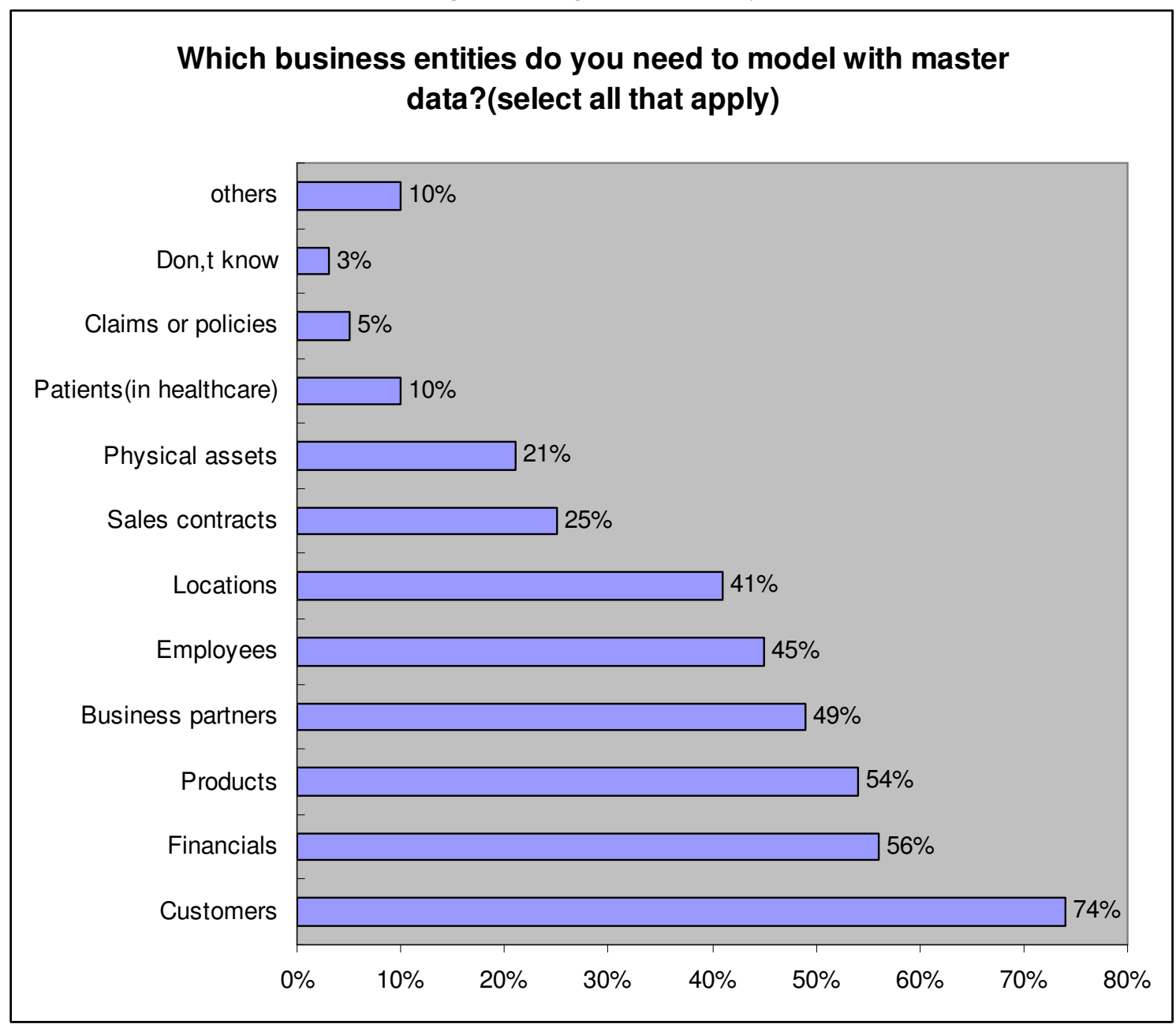

Based on 2,982 responses from 741 respondents.

Figure.3. 


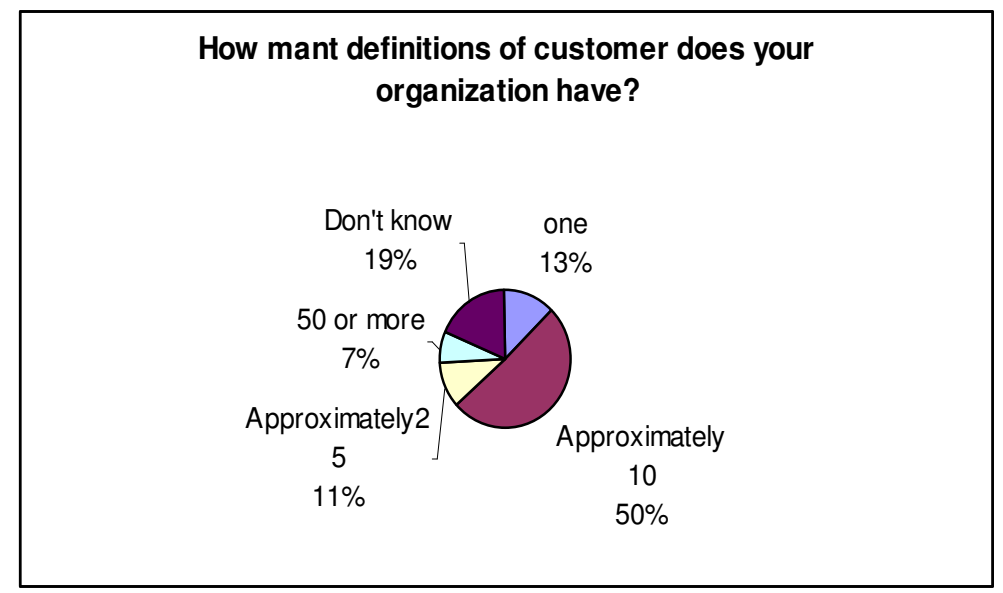

\section{Based on 741 respondents.}

From the survey, we have realized that customer master data plays an important role in most organizations. Customer master data is mostly in the forefront in any service oriented organization. Also it is challenging as the data is gathered from disparate sources e.g. one organization is trying to implement customer MDM solution by integrating 30 ERP sources.

Then from our contact circle, we have chosen 3 companies. Managers who are dealing with MDM affairs from 3 companies were selected. Those selected companies are in the process of implementing MDM solutions for customer master data. Also these companies work in global environment having their presence in USA Europe and Asia Pacific. They have different enterprise systems for different applications.

Table 1: Summary of Interviewees' organization.

\begin{tabular}{|llll|}
\hline Company & Business Area & Geography & Role \\
\hline A & Healthcare & Asia Pacific & R\&D Scientist \\
B & Retail & India & Business Analyst \\
C & IT & USA ,Europe, & Practice Manager \\
& & Asia Pacific & \\
& & & \\
& & & \\
\hline
\end{tabular}

\section{Results}

We interacted the executives from the companies and the interview was done amicably. It is very interesting and their responses to the questionnaire are recorded. Manager ' $A$ ' was very much friendly in conversion; he is a keen listener .If he is not sure about the things, he was replying 'Not clear'. Manager B was very enthusiastically answering our queries. Manager C was a techie; he has solid knowledge of the root of the problems. The excerpts from the interview was listed below 
International Journal of Database Management Systems ( IJDMS ), Vol.3, No.2, May 2011

Table 2:Interviewees' response on challenges.

\begin{tabular}{|c|c|}
\hline Challenges faced by A & $\begin{array}{l}\text { Data definitions are different in different applications. } \\
\text { Data are in different format causing standardization and } \\
\text { integration cumbersome. } \\
\text { Data ownership is not strictly practiced. } \\
\text { Data transfer cause errors. } \\
\text { Integration between applications is laborious. } \\
\text { All the fields while integrating from disparate sources are not } \\
\text { transferring. } \\
\text { Confusion between ETL team and MDM personnel } \\
\text { Change Management among the stakeholders. } \\
\text { Presence of duplicate CDI hubs. }\end{array}$ \\
\hline Challenges faced by B & $\begin{array}{l}\text { Data is increasing rapidly, it requires data quality improvements. } \\
\text { Master data is not defined properly causing confusion on } \\
\text { understanding. } \\
\text { No common data model. } \\
\text { Data maintenance is laborious. } \\
\text { No standard process for updating data. } \\
\text { No ownership of data. } \\
\text { Several CDI systems cause integration process challenging. } \\
\text { Attributes integrity is not maintained while integrating }\end{array}$ \\
\hline Challenges faced by $\mathrm{C}$ & $\begin{array}{l}\text { Old data are not in proper format. } \\
\text { Defining master data is difficult. } \\
\text { Data consolidation is laborious. } \\
\text { Data maintenance process is not defined. } \\
\text { Developing the interface between some applications are very } \\
\text { difficult. } \\
\text { Some data and data model are rarely used. } \\
\text { Data transfer is very time taking. } \\
\text { Lack of common unique identifier. } \\
\text { No common object methodology. } \\
\text { Impossible to decide which version of customer profile is } \\
\text { accurate. }\end{array}$ \\
\hline
\end{tabular}

MDM is relatively a new concept; still a lot of thing has to come front in this area. They revealed that the benefits of MDM are recognized and the management has invested heavily for this project. But they are very sure on return of investment. As the interview was about MDM ,but they were mixing it with data management activities like CRM, data warehouse.

The interviews revealed that all companies more or less face some common challenges. Everyone was raising the issue of data quality problem. According to them it is the root of all big issues. This affects data ownership model. They prioritized in understanding the business environment and business model. 
International Journal of Database Management Systems ( IJDMS ), Vol.3, No.2, May 2011

\section{Conclusion}

The challenges related to Master data customer has been studied. From the study it is clear that the main challenges are presence of duplicate CDIs, data and application integration, data consolidation, data governance challenges, metadata management. As MDM is about implementing a technology, also we got a view that the problems were not only technology based, business initiatives is needed in the MDM arena. Technology is myopic.

MDM is cross functional, it benefits from an organization that fosters collaboration between business and IT. Rapidly changing technology drive periodic application reengineering but the business customer remain with the organization .Clean, consolidated and accurate master data seamlessly propagated throughout the enterprise can save millions of dollars, increase market base, improve customer loyalty and support sound corporate governance.

A realistic research is needed to find out the actual state of MDM practices, current trend and optimization of MDM solutions. We have selected only 3 companies in our survey. It was difficult to identify companies following MDM practices in our vicinity and in some cases the managers hesitate to disclose their business strategy and about their clients. Future research may be carried out by involving hundreds of companies so that their responses could be analyzed by mathematically or statistically. This is possible if some leaders in the MDM sphere like Microsoft, IBM, Oracle, SAP could sponsor and participate in the findings.

\section{References}

[1] Berson, A. and Dubov, L. (2007), Master Data Management and Customer Data Integration for aGlobal Enterprise, McGraw-Hill, New York, NY.

[2] Boyd, M. (2006), "Product information management - forcing the second wave of data quality", available at: ww.thecopywritingpro.com/pages/samples_assets/2nd-waveDQ.pdf(accessed 27 April 2010).

[3] Breuer, T. (2009), "Data quality is everyone's business - designing quality into your datawarehouse - part 1", Journal of Direct, Data and Digital Marketing Practice, Vol. 11,pp. 20-9.

[4] Butler,David., Stackowiak,Bob., "Master Data Management", Oracle Corporation.available at www.oracle.com.

[5] Dayton, M. (2007), "Strategic MDM: the foundation of enterprise performance management",Cutter IT Journal, Vol. 20 No. 9, pp. 13-17.

[6] Dreibelbis,Allen , Hechler,Eberhard, Milman ,Ivan(2009), "Enterprise Master Data Management",Pearson Education.

[7] Dumas, M., Aalst, W. and Ter Hofstede, A. (2005), Process-aware Information Systems: BridgingPeople and Software Through Process Technology, Wiley, Hoboken, NJ.Managing onemaster data161

[8] Gartner MDM Summit,(2011),UK 
International Journal of Database Management Systems ( IJDMS ), Vol.3, No.2, May 2011

[9] Knolmayer, G. and Ro"thlin, M. (2006), "Quality of material master data and its effect on theusefulness of distributed ERP systems", Lecture Notes in Computer Science, Vol. 4231,pp. 362-71.

[10] Lee, Y.W., Pipino, L.L., Funk, J.D. and Wang, R.Y. (2006), Journey to Data Quality”, MIT Press, Cambridge, MA.

[11] Loshin, D. (2009), Master Data Management, Morgan Kaufmann, Burlington,MA.

[12] Malcolm, Chisholm(Dec 2010),'The Governance Challenge for Master Data Management”, Data Governance Conference, Orlando, Florida

[13] "MDM Fundamentals and Best practices",www.elearningcurve.com

[14] Moss, L. (2007), "Critical success factors for master data management”, Cutter IT Journal, Vol. 20No. 9, pp. 7-12.

[15] Rachuri, S., Subrahmanian, E., Bouras, A., Fenves, S., Foufou, S. and Sriram, R. (2008), "Information sharing and exchange in the context of product lifecycle management: role ofstandards", Computer-Aided Design, Vol. 40 No. 7, pp. 789-800.

[16] Rittman,Mark.’Introduction to Master Data Management”.www.rittmanmead.com

[17] Russon,Philip. (2006), Master Data Management - TDWI Best practice Report available at www.tdwi.org.

[18] Schumachar, Scott (Oct 2010),"MDM: Realizing the same benefits through different implementations", www.initiatesystems.com

[19] Toronto MDM Summit.(2008),"MDM Challenges and solutions from the real world" available at www.adastracorp.com

[20] White, A., Newman, D., Logan, D. and Radcliffe, J. (2006), "Mastering master datamanagement", available at: http://kona.kontera.com/IMAGE_DIR/pdf/MDM_gar060125_MasteringMDMB.pdf (accessed 12 April 2010).

[21] Wolter,Roger.,Haselden,Kirk.(2006),A White paper on MDM, Microsoft Corporation.

[22] Yang, X., Moore, P.R., Wong, C.-B., Pu, J.-S. and Chong, S.K. (2007), "Product lifecycle information acquisition and management for consumer products", Industrial Management \& Data Systems, Vol. 107 No. 7, pp. 936-56. 